\title{
ECOSSISTEMA DE INOVAÇÃO EM BIONEGÓCIO NA REGIÃO NORDESTE DO BRASIL
}

\author{
INNOVATION ECOSSYTEM IN BIO-BUSINESS IN \\ NORTHEASTERN BRAZIL
}

\begin{abstract}
Ana Paula André Barros
IF SERTÃO-PE / Renorbio - Universidade Federal da Bahia

paulandrebarros@gmail.com
\end{abstract}

Erika Samantha Santos de Carvalho

Renorbio - Universidade Federal da Bahia

erikasamantha2@hotmail.com

Paulo Romano Cruz Correia

Renorbio - Universidade Federal da Bahia

paulo.romano85@hotmail.com

Renata Quartieri Nascimento

Renorbio - Universidade Federal da Bahia

rqnutri@gmail.com

Ronaldo Carvalho da Silva

Renorbio - Universidade Federal da Bahia

rcarvalhos20@gmail.com

Marcos Alberto Castelhano Bruno

Renorbio - Universidade Federal da Bahia

marcos.acbruno@gmail.com

A interação entre bionegócios promove evolução do ecossistema de inovação. Analisar como estes negócios se relacionam possibilita entender o que favorece o surgimento de novos negócios e os casos de sucesso. $O$ presente 
estudo analisou o ecossistema de inovação existente na região nordeste do Brasil, buscando caracterizar o ambiente de inovação. Os dados foram buscados em fontes de informações primárias e secundárias. Na região nordeste a legislação estabelece um ambiente de incentivo ao surgimento de novos negócios; as instituições de fomento favorecem o desenvolvimento de pesquisas e desenvolvimento de novos negócios. As Universidades, Parques Tecnológicos e Institutos de pesquisa, em parceria com empresa privadas, fazem com que os bionegócios sejam impulsionados. Há dificuldade no acesso aos dados produzidos pelas entidades supracitadas e ausência de interação entres todos os componentes do ecossistema de inovação. Assim, o gargalo encontrado foi a deficiência na gestão da inovação.

Palavras-chave: Bioeconomia, Biotecnologia, Empreendedorismo, Gestão.

\section{ABSTRACT}

The interaction between bio-business promotes evolution in the innovation ecosystem. Evaluate how these businesses interact enables us to understand the factors related to the growth of new business and the success cases. The present study characterized the innovation ecosystem present in the Brazilian northeastern region. The data search was in primary and secondary sources. In northeastern Brazil, the legislation establishes an incentive environment for new business; with the funding agencies favoring the research and development area. The universities, technology parks, and research institutes, with a partnership with private companies, promote the bio-business impulse. There are difficulties to obtain data access from the before cited institutions and there is no interaction between all the innovation ecosystem components. Therefore, the bottleneck found was the deficiency in innovation management.

Keywords: Bioeconomics, Biotechnology, Entrepreneurship, Management.

JEL Classification: O32 Management of Technological Innovation and R\&D. 


\section{INTRODUÇÃO}

O sucesso de inovações tecnológicas ou organizacionais, em setores de atividade econômica está relacionado ao ecossistema de negócio no qual está inserido o processo de gestão da inovação. No Brasil, essa constatação levou à inserção da inovação na pauta da política nacional no final dos anos 1990 e início dos anos 2000.

$\mathrm{O}$ aparato jurídico-institucional tem sido ampliado e atualizado, com destaque para sanção da Lei da Inovação e da criação do Sistema Nacional de Inovação, estabelecendo as diretrizes e regulamentação para criação e consolidação do ecossistema brasileiro de inovação.

No Brasil, a biotecnologia tem possibilitado a criação de bionegócios que influencia na saúde, dinamismo e a eficácia do ecossistema de inovação que possibilita o êxito da competitividade das organizações da Nação nos bionegócios.

O ecossistema de inovação congrega a integralidade dos atores de uma cadeia produtiva, desde a geração do conhecimento científico pelas instituições de ensino e pesquisa, passando pelos agentes financeiros de fomento, instituições de pesquisa tecnológica, organizações do terceiro setor, outros eventuais agentes da sociedade civil e organizações de produção.

O Brasil, reconhecido internacionalmente pela qualidade e quantidade dos conhecimentos científicos que produz, demonstra ainda baixa capacidade de aproveitamento da plenitude do potencial contido nessa produção científica em benefício socioeconômico.

Neste contexto, este trabalho teve como objetivo caracterizar o ecossistema de inovação em bionegócios no qual está inserida a Rede Nordeste de Biotecnologia e identificar os fatores de gestão relevantes que agem na interação entre os agentes do ecossistema de inovação do nordeste brasileiro.

\section{CONTEXTUALIZAÇÃO}

O sucesso da gestão dos negócios é evidenciado pela observação dos resultados de duas práticas traduzidas como "máximas" e consagradas na literatura como axiomas: "A inovação é vital para competir" e "Saber cooperar é vital para inovar". 
A evolução da realidade socioeconômica torna a prática do "Saber cooperar é vital para inovar" uma questão relevante para a competitividade, em termos microeconômico, de empresas, ou agregado, de setor econômico, país ou região. Essa constatação generalizada para os vários segmentos da atividade produtiva, indústria e serviços, repercute mais expressivamente em segmentos onde a inovação tecnológica carrega maior dose de incerteza, como acontece em ramos da biotecnologia (Guedes, 1998).

Assim, o "Saber cooperar" - "trabalhar juntos" é um dos principais desafios organizacionais da atualidade, ou seja, trabalhar de forma colaborativa para ser competitivo (Bruno \& Vasconcellos, 2013). Esse tipo de situação organizacional requer dos gestores uma habilitação para gerir sistemas de negócios multiagentes com alto grau de complexidade gerencial.

Uma das iniciativas conhecidas desse tipo de arranjo organizacional são os Distritos Industriais Italianos (Boari \& Liparini, 1999). Nesses, há um cuidado específico com a relação inovação e competitividade, dos agentes econômicos individualmente e do Distrito como um todo. Cada Distrito, em função de sua especificidade de atuação econômica, organiza seu ecossistema de inovação da forma mais eficiente possível. Regularmente são envolvidos no ecossistema de inovação de um Distrito os agentes econômicos nele atuantes e externos. Não raro, há estruturas para estímulo à inovação, tal como incubadoras e ações de estímulo ao desenvolvimento de startups.

Conceitos associados à gestão desse tipo de ambiente de negócios como o de inovação aberta (Chesbrough, 2003), têm sido objeto de interesse de pesquisa em administração estratégica.

A literatura também tem se dedicado à questão dos modelos de negócios, nos quais a competitividade é sensível à inovação (Johnson \& Christensen \& Kagermann, 2008).

Em meados dos anos 90, vários autores se dedicaram a pesquisas voltadas à geração de conhecimentos e instrumentos de análise para contribuir à gestão de ecossistemas de inovação com intensa cooperação entre os agentes (Yoshino \& Rangan, 1995; Doz \& Hamel, 1998).

Entre os mais complexos ecossistemas de inovação, baseados em estratégia de colaboração multiagentes está o caso do modelo de negócios da Petrobras, denominado Projeto Centro de Excelência, utilizado para movimentos estratégicos daquela Empresa, 
entre eles o Projeto do Pré-sal. O processo de gestão desse tipo de modelo estratégico foi estudado via aplicação do modelo conceitual de gestão de ambientes de negócios com pronunciada cooperação entre os agentes (Bruno \& Vasconcellos, 2003).

A estratégia de cooperação é comumente empregada para internacionalização de bionegócios, ampliando a dimensão geográfica dos ecossistemas de inovação. Bruno \& Waack (1992) apresentam um desses processos de internacionalização: o desenvolvimento conjunto pelo Brasil e Argentina da produção de batata-semente por biotecnologia.

\section{REVISÃO BIBLIOGRÁFICA}

Desde os tempos mais remotos os seres humanos utilizaram microrganismos para preparar bebidas, alimentos e vestimentas. A descoberta dos processos fermentativos foi um acontecimento que ocorreu várias vezes em momentos diferentes da história da humanidade. A fermentação trazia duas vantagens fundamentais: a eliminação das substâncias tóxicas de alguns grãos e a preservação dos alimentos (Vicenzi, 2011). Ou seja, os seres humanos a biotecnologia precede seu conceito.

O termo Biotecnologia data de 1917 com Karl Ereky que engloba todas as técnicas que utilizam organismos vivos em particular, animais, plantas ou microrganismos ou qualquer tipo de material biológico que pode ser assimilado aos microrganismos ou parte dos mesmos, para provocar neles mudanças orgânicas (Glick \& Pasternak, 2003).

A evolução da biotecnologia ganha impulso na segunda metade dos anos 1970, quando as possibilidades de manipulação gênica foram ampliadas pelas técnicas de DNA recombinante e de anticorpos monoclonais, foi caracterizada por uma multiplicação de descobertas e possibilidades científicas e tecnológicas em escala geométrica. A definição do termo biotecnologia foi ampliado para um conjunto de tecnologias habilitadoras (enabling technologies) que possibilitam utilizar, alterar e otimizar organismos vivos ou suas partes, células, organelas e moléculas, para gerar produtos, processos e serviços em saúde humana e animal, agricultura e meio ambiente (Judice \& Baêta, 2005; Silveira et al.,2002). A biotecnologia acelera os processos de inovação.

A inovação pode ser concebida como uma criação ou renovação de algo preexistente, através de estudos, observações e persistência, buscando soluções, que 
sejam práticas e simples, ao passo que possam ser facilmente entendidas e aceitas pelos consumidores (Bessant, 2009). A dinâmica da inovação é composta por três fases: a invenção, uma ideia potencialmente aberta para a exploração comercial; a inovação, exploração comercial e; a difusão, propagação de novos produtos e processos pelo mercado (Ferreira \& Ruffoni \& Carvalho, 2018).

Com o advento da tecnologia digital, a sociedade passou a ser mais conectada, gerando uma nova forma de pensar e agir, tanto em nível organizacional, quanto individual, apresentando ao mundo uma nova proposta de valor, fortemente baseada no conhecimento (Barros, 2011). Neste contexto, a sociedade do conhecimento é mantida pelos agentes locais que devem desenvolver uma cultura direcionada à inovação, dedicando-se a pensar em como gerir o conhecimento por meio da tecnologia da informação, da organização do trabalho, da gestão da inovação, gestão de pessoas e gestão dos recursos (Korobbinski, 2001).

Especialmente a inovação tecnológica é tida atualmente como essencial nas estratégias de diferenciação, competitividade e crescimento em um número cada vez maior de negócios. A adoção de estratégias e práticas inovadoras nas empresas está estreitamente associada à busca de diferenciações capazes de produzir produtos e serviços para o mercado, que gerem vantagens competitivas sustentáveis em relação a seus concorrentes (Vilha, 2010). Desta forma, a inovação tecnológica origina-se na necessidade de solução de um problema tecnológico, em que simplesmente os conhecimentos disponíveis até o momento não são suficientes para resolver. (Dosi, 1988; Ribeiro, 2001).

Nessa perspectiva, o sucesso econômico de cada unidade empresarial e região passa a depender da sua capacidade de se especializar naquilo que consiga estabelecer vantagens competitivas efetivas e dinâmicas, decorrente dos seus próprios atributos e de sua capacidade continuada de inovar (Crocco \& Diniz \& Santos, 2006).

A Lei de Inovação Tecnológica (Lei no 10.973/2004) no Brasil, que entrou em vigor desde dezembro de 2004, é um instrumento de fomento à inovação e à pesquisa científica e tecnológica no ambiente produtivo, com vistas à capacitação e ao alcance da autonomia tecnológica e ao desenvolvimento industrial do País. Esta ferramenta promove ainda a cooperação para viabilização de empresas emergentes, por meio do processo de incubação, e a colaboração com empresas consolidadas (Matias-Pereira \& Kruglianskas, 
2005). No ano de 2018 , foi decretado a regulamentação de dispositivos desta Lei que se refere ao estabelecimento de medidas de incentivo à inovação e à pesquisa científica e tecnológica no ambiente produtivo, com vistas à capacitação tecnológica, ao alcance da autonomia tecnológica e ao desenvolvimento do sistema produtivo nacional e regional. A nível estadual também há legislação de incentivo (Brasil, 2018).

Neste cenário, conceituamos um Sistema de Inovação como todos os fatores econômicos, políticos, sociais, institucionais e organizacionais, responsáveis pela geração, uso, difusão, absorção, importação ou modificação de conhecimentos ou de inovações (Smith,1997).

O Sistema Nacional de Inovação (SNI) é uma rede de entidades que têm como interesse comum desenvolver a inovação no País (Leite, 2005). Trata-se de uma estratégia governamental de integração dos diferentes atores, como universidades, centros de pesquisa, empresas, governo e ONGs. Para a efetividade deste Sistema, este deve ter em seu centro efetivo a Empresa visto que ela é o berço da aplicação das inovações e, consequentemente, gera riqueza para a sociedade. Podendo, por exemplo, favorecer financiamentos para empresas que investem em Ciência e Tecnologia, formação de recursos humanos de qualidade e medidas econômicas que reduzam os custos para produzir inovação, como pode-se observar no Mapa do Sistema Brasileiro de Inovação apresentado pela ANPEI (2014), conforme a Figura 1.

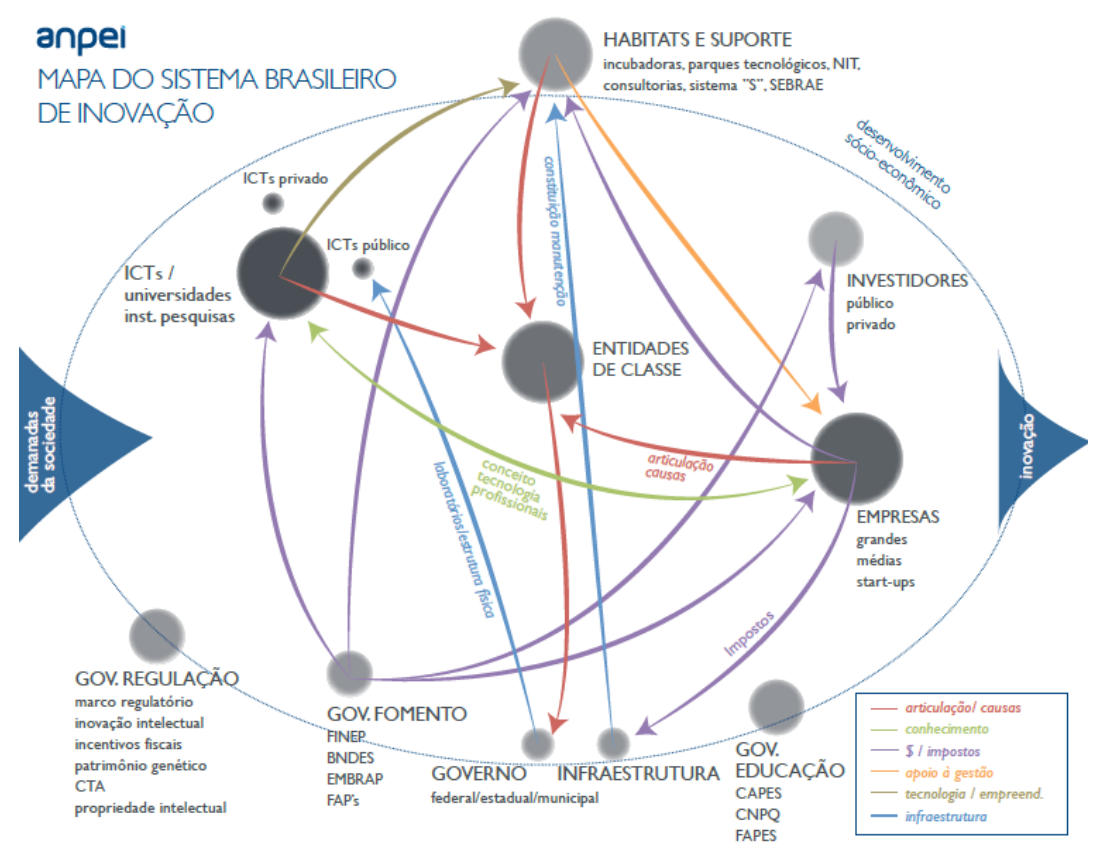


Figura 1. Mapa do Sistema Brasileira de Inovação, ANPEI, 2014.

No SNI o Estado tem o papel de aplicar e fomentar políticas públicas de ciência e tecnologia; às universidades/institutos de pesquisa, cabe a criação, disseminação do conhecimento e a realização de pesquisas; e, as empresas são responsáveis pelo investimento na transformação do conhecimento em produto (Villela \& Magacho, 2009).

O Modelo de hélice tripla, desenvolvida a partir dos trabalhos de Etzkowitz \& Leydesdorff (1997), estuda estas relações de cooperação entre universidades, indústria e governo, colocando a infraestrutura científico-tecnológica como agente essencial em economias baseadas no conhecimento (Torres \& Botelho, 2018; Villela \& Magacho, 2009).

O desenvolvimento tecnológico e a inovação de um país dependem, em grande parte, da formação de recursos humanos capacitados, bem como de investimentos consistentes, contínuos, de longo prazo e de porte (Felipe, 2007). As universidades e os centros de pesquisas são agentes fundamentais nos sistemas de inovação nacionais e regionais, por serem responsáveis pela formação de mão de obra qualificada e por se constituírem em fontes de conhecimento fundamental e prático para o setor de produção (Torres \& Botelho, 2018).

A pesquisa científica é a fonte básica de conhecimentos para o desenvolvimento de produtos e serviços biotecnológicos e gerou o modelo empresarial clássico do setor: o cientista-empresário e a típica, micro e pequena empresa spin-off universitária (Judice \& Baêta, 2005).

Um dos mecanismos que viabilizam a transformação do conhecimento em produtos, processos e serviços é a incubação de empresas, na qual é imprescindível a participação ativa da comunidade que realiza pesquisas e atividades tecnológicas, em instituições de cunho tecnológico. Em um contexto onde o conhecimento, a eficiência e a rapidez no processo de inovação passam a ser reconhecidamente os elementos decisivos para a competitividade das economias, o processo de incubação é crucial para que a inovação se concretize em tempo hábil para suprir as demandas do mercado. Neste contexto, existem diversos tipos de incubadoras: as tradicionais, as de base tecnológica, as mistas, as culturais, as sociais, as agroindustriais e as de serviços. As incubadoras de base tecnológica representam a maioria das existentes no país (40\% do total) (ANPROTEC, 2005). 
Portanto, as incubadoras constituem ambientes especialmente planejados para acolher empresas nascentes, bem como aquelas que buscam a modernização das suas atividades, de forma a transformar ideias em produtos, processos e serviços que consiste na incubação conferindo às empresas condições favoráveis para detectar tendências, incorporar novidades e acompanhar as mudanças de mercado, principalmente atuando como interface entre o setor acadêmico e produtivo (ANPROTEC \& SEBRAE, 2002).

No Brasil, a transferência para o setor produtivo de conhecimento e de tecnologias geradas em centros de pesquisa e universidades assume um papel fundamental dentro de uma estratégia de aumento da competitividade da indústria em busca de novos mercados e da própria sobrevivência no mercado nacional e internacional (Ribeiro, 2001).

Empresas e trabalhadores são mais produtivos em grandes e densas áreas urbanas do que em outras localidades. Uma parte significativa disso, pode ser explicada pelas economias de aglomeração. Desta forma, a integração do conhecimento pode ocorrer por meio de relações informais estabelecidas entre os agentes econômicos devido à proximidade geográfica e pela mobilidade de mão de obra entre empresas. Além disso, entre as vantagens da aglomeração, podemos destacar a maior diversificação de bens, serviços, tecnologias e conhecimentos e o ambiente rico em criatividade e troca de informações e experiências entre diferentes setores (Silva \& Furtado, 2017).

No universo supracitado, emergem a bioeconomia que pode ser entendida como a biotecnologia aplicada à economia. Desta forma, a utilização da biotecnologia pode ser aplicada na diminuição dos custos de produção, substituindo produtos sintéticos por organismos mais seletivos e por produtos biodegradáveis e/ou renováveis, para a criação de produtos na agricultura e na indústria (Miguel, 2007).

A ampliação do conceito de bioeconomia perpassa pelo conceito de bionegócio que são atividades econômicas voltadas à extração/beneficiamento e comercialização de insumos ou produtos que apresentem na sua composição recursos da biodiversidade, sejam eles na sua forma mais bruta ou tecnologicamente modificada. Esta ampliação é importante para incorporar diversas empresas que não utilizam tecnologia de ponta, mas fazem uso da biotecnologia em seus negócios (Sousa \& Figueiredo, 2015). 
Bionegócio pode ser entendido como atividades econômicas voltadas à extração, beneficiamento e comercialização de insumos ou produtos que apresentem na sua composição recursos da biodiversidade que condicionem o valor agregado do produto, sejam eles na sua forma mais bruta ou tecnologicamente modificada (Sousa, 2014).

Nesta perspectiva, Araújo Filho (2010) propõe a caracterização e divisão dos bionegócios em quatro grupos de acordo o grau de tecnologia usado no processamento destes produtos:

Grupo I - Uso da biodiversidade no estado in natura ou submetida a processos de beneficiamento simples, centrados em características mecânicas inclui atividades com uso econômico do valor "cultural" da biodiversidade. São exemplos a comercialização de frutos e peixes frescos, folhas, raízes, cascas, flores, artefatos com ênfase estética ou decorativa, moda, turismo.

$\checkmark$ Grupo II - Produtos que utilizam processos baseados em conhecimento consagrado, com domínio disseminado (extração, concentração, filtração, destilação, separação etc.), que podem demandar o uso de boas práticas. Neste Grupo incluem-se produtos como bebidas, concentrados, doces, polpas, pós;

Grupos III - Abrange processos químicos e/ou biológicos de maior complexidade, cuja demanda por conhecimento especializado implica em aumento de risco técnico; o desenvolvimento do produto exige testes ou ensaios. Alcança matérias-primas e produtos de perfumaria, cosméticos, fitoterápicos e fitocosméticos, bioenergia, reprodução de plantas, alimentos industrializados;

$\checkmark$ Grupo IV - Utilização de processos associados à chamada biotecnologia moderna, que tem como base a biologia molecular e a engenharia genética Organismos geneticamente modificados, microrganismos industrializados e alimentos funcionais são exemplos de produtos deste grupo.

Desta forma, os bionegócios incorporam o uso sustentável dos recursos naturais, sendo importante o reconhecimento dos direitos das comunidades tradicionais que possuem o conhecimento e detém a tecnologia, em seu modo mais genuíno (Berger Filho \& Sparemberger, 2008). Além disso, os bionegócios são impulsionados pela base das 
cadeias produtivas da maioria dos bioprodutos que se inicia nas Reservas de Desenvolvimento Sustentável, Reservas de Extrativismo Sustentável, Florestas Nacionais, Terras Indígenas e Unidades de Reforma Agrária Sustentável (Vasconcellos \& Frickman, 2010).

Com base nas informações supracitadas pode ser percebido que o desenvolvimento em âmbito nacional e regional está atrelado à inovação e ao desenvolvimento de novos negócios, podendo ser bionegócios.

\section{METODOLOGIA}

De acordo com Gil (2010), este estudo, tem caráter exploratório e descritivo. Trata-se de uma pesquisa aplicada direcionada à aquisição de conhecimentos do ecossistema de inovação que fomente, em última análise, o aumento da eficiência da aplicação dos conhecimentos da academia em desenvolvimento de bionegócios, em particular, na Região do Nordeste do Brasil.

O desenvolvimento desta pesquisa constou das seguintes etapas:

- $\quad$ Revisão bibliográfica nos temas de interesse do objeto pesquisado;

- Levantamento de dados, de natureza primária e secundária;

- $\quad$ Apresentação dos resultados obtidos no levantamento de dados;

- Discussão dos resultados; e,

- $\quad$ Considerações finais.

\subsection{Levantamento de dados primários}

O levantamento de dados primários foi feito junto a um conjunto de gestores de empresas inovadoras com experiência na gestão de inovação.

Esses gestores estão vinculados às seguintes organizações:

- Startups: Inovale Tecnologia, Juazeiro, BA; Linking Dotz, São Paulo, SP;

- Empresa (porte médio): GranBio, São Paulo (sede) e Alagoas (unidade industrial);

- Corporações (grande porte): Braskem, São Paulo (sede) e unidades regionais na Alemanha, México e E.U.A; Solvay, Bruxelas (sede) e unidades em vários países do Mundo, incluindo o Brasil (Solvay e ex-Rhodia). 
O objetivo central do levantamento de dados primários foi a identificação dos aspectos chave do ecossistema empresarial de inovação da organização. Este levantamento foi feito por meio de entrevista aberta por tópicos agregados nas seguintes dimensões:

- Estratégia empresarial: inovação e competitividade empresarial (inovação: novos negócios; novos mercados; estratégias empresariais praticadas para acesso à inovação: aquisição, fusão, cooperação);

- Organização para interação externa em inovação (fontes de financiamento de recursos para inovação; interação com ICTs; política de formação de profissionais para interação em inovação (técnica e gerencial); iniciativas/mecanismos para interação com ambiente mobilizador para novos negócios: startups, incubadoras, polos tecnológicos, etc.; relacionamento com entidades de classe atuantes no estímulo à inovação);

- Estrutura interna para a atividade de inovação (nível diretivo responsável por inovação; inovação e estrutura organizacional; mecanismo para estabelecer diretrizes políticas para inovação; decisão sobre infraestrutura: própria ou em colaboração; processo de gestão da inovação: geração de ideias e seleção de projetos).

Complementarmente, foram feitos contatos com gestores do Instituto Euvaldo Lodi (IEL), Superintendência Nacional/CNI e Superintendência Regional Bahia, Federação da Indústria do Estado da Bahia (FIEB). Essa estrutura tem entre suas responsabilidades a coordenação das atividades do Movimento Empresarial pela Inovação (MEI). A MEI é cogestora da Empresa Brasileira de Pesquisa Industrial e Inovação (EMBRAPII), órgão da estrutura de fomento de P, D \& I no País e descrita mais adiante neste trabalho.

Foram realizadas também visitas e contatos com gestores do:

- Instituto de Biotecnologias da Saúde do Senai/Cimatec, Salvador, BA;

- Inovale Tecnologia, Juazeiro, BA; e,

- Escola do Vinho/Instituto Federal do Sertão do Pernambucano, Petrolina, PE.

\subsection{Levantamento de dados secundários}


O objetivo central do levantamento de dados secundários foi a identificação dos componentes do Ecossistema de Inovação Regional Nordeste, nas dimensões: Academia, Governo e Entidades.

O levantamento foi feito por intermédio de material institucional disponível em meio impresso e digital.

Fizeram parte do objeto do levantamento organizações, entidades e instituições públicas e privadas, nacionais, regionais e locais cujo papel, ações e políticas estejam vocacionadas para o ecossistema de inovação da Região Nordeste voltados para a geração de bionegócios.

\section{RESULTADOS}

\subsection{Caracterização do ecossistema de inovação em negócios na Região Nordeste}

Em todo o mundo observa-se o desenvolvimento de atividades intensivas em conhecimento, nas quais o processo de inovação é fundamental. São exemplos as novas Tecnologias da Informação e Comunicação (TIC), a nanotecnologia, as pesquisas com células-tronco e outras. Assim, o objetivo do presente estudo é discutir as potencialidades do setor de Biotecnologia para o desenvolvimento da região Nordeste do Brasil. Foi analisada a distribuição das atividades de Biotecnologia no Brasil e no Nordeste brasileiro. Esta região possui universidades com tradição em pesquisas e podem assumir um papel de destaque na produção de ciência e tecnologia, e contribuir para as atividades de Biotecnologia no Brasil.

O Brasil ocupa a $69^{\circ}$ posição no ranking mundial em Inovação nos dois últimos anos (2016 e 2017), dentre 127 países estudados, sendo considerado uma das piores posições do país, perdendo para países como: Suíça, Estados Unidos, Reino Unido, Suécia e Holanda (CNI, 2017).

É necessário considerar que mesmo com a melhoria do desemprenho brasileiro em termos de insumos de inovação, percebe-se tendência oposta em termos de produtos de inovação, especialmente depois de 2014. No Brasil a queda abrupta na taxa de eficiência da inovação é crescente: se, em 2011, ocupávamos a 7. a posição em eficiência inovadora, seis anos mais tarde, em 2017, o Brasil passou a ocupar a 99. a posição, entre 127 países estudados (CNI, 2017). 


\subsection{Estímulo ao desenvolvimento de novos negócios: infraestrutura na Região Nordeste}

Segundo Abreu \& Campos Neto (2016-07), em o Panorama das aceleradoras e Startups no Brasil: Uma amostra de 53 aceleradoras e incubadoras:

Incubadoras e aceleradoras do país estão representadas, com uma concentração maior nas regiões Sudeste (aprox. 60\%) e Sul (aprox. 25\%);

$\checkmark \quad$ Entre os demais, os setores mais comuns são tecnologia da informação e comunicação (TIC), saúde e energia;

$\checkmark \quad$ As fontes mais comuns para financiamento das operações incluem governo, organizações filantrópicas e taxas cobradas dos negócios acelerados

As fontes de financiamento com a maior contribuição média aos orçamentos operacionais são o governo (60\%) e organizações filantrópicas (50\%);

$\checkmark \quad$ As aceleradoras brasileiras que fazem parte da amostra possuem programas com duração mais longa do que aquelas que atuam em outros países;

$\checkmark \quad$ Os respondentes estão sediados em 14 estados diferentes e divididos entre 25 cidades. A maioria está localizada na região Sudeste e a região Nordeste está em terceiro lugar.

$\checkmark \quad$ Poucos respondentes geraram receita a partir dos retornos financeiros de investimentos em participação (equity) ou de taxas cobradas dos investidores;

$\checkmark \quad$ Adicionalmente, 23 respondentes (45\%) declararam ser afiliados a uma universidade.

No livro 10 Mil Startups (2017) de Felipe Matos lançado na CASE 2017, foi relatado que: Santa Catarina é o segundo estado com maior número absoluto de startups, seguido por Minas Gerais e Rio de Janeiro, perdendo apenas para São Paulo. Outra surpresa veio do Ceará, que apareceu como primeiro colocado da região Nordeste, na frente de Pernambuco, na oitava e nona posições, respectivamente.

$\mathrm{Na}$ região Nordeste, o Estado de Pernambuco sozinho representa 4,2\% das empresas no Brasil, totalizando 10 empresas. Outro cluster pode ser observado na área 
costeira da Região Nordeste do Brasil, nos Estados de Sergipe, Alagoas, Pernambuco e Paraíba (CEBRAP, 2011).

De acordo com estimativas apresentadas pelo MCTI (2014) os parques científicos e tecnológicos do país apresentam um total de 939 empresas, com uma concentração na região Sul (40\%), Nordeste (32\%) e Sudeste (25\%). As regiões Centro-Oeste e Norte congregam somente $3 \%$ das empresas. A Figura 2 apresenta a quantidade de empresas instaladas nos parques tecnológicos, distribuídas pelas cinco regiões brasileiras.

Analisando as 94 iniciativas registradas pela pesquisa, verifica-se uma maior concentração desses habitats de inovação na região Sudeste e Sul. Na região Sudeste são 39 (41,5\%) iniciativas e, na região Sul, 35 (37,2\%). Assim, praticamente 4 de cada 5 iniciativas de parques científicos e tecnológicos estão nessas regiões. Na região CentroOeste há $8(8,5 \%)$ iniciativas de parques, na região Nordeste há $7(7,5 \%)$ e na região Norte há 5 (5,3\%). A distribuição de parques por região pode ser observada na Figura 2.

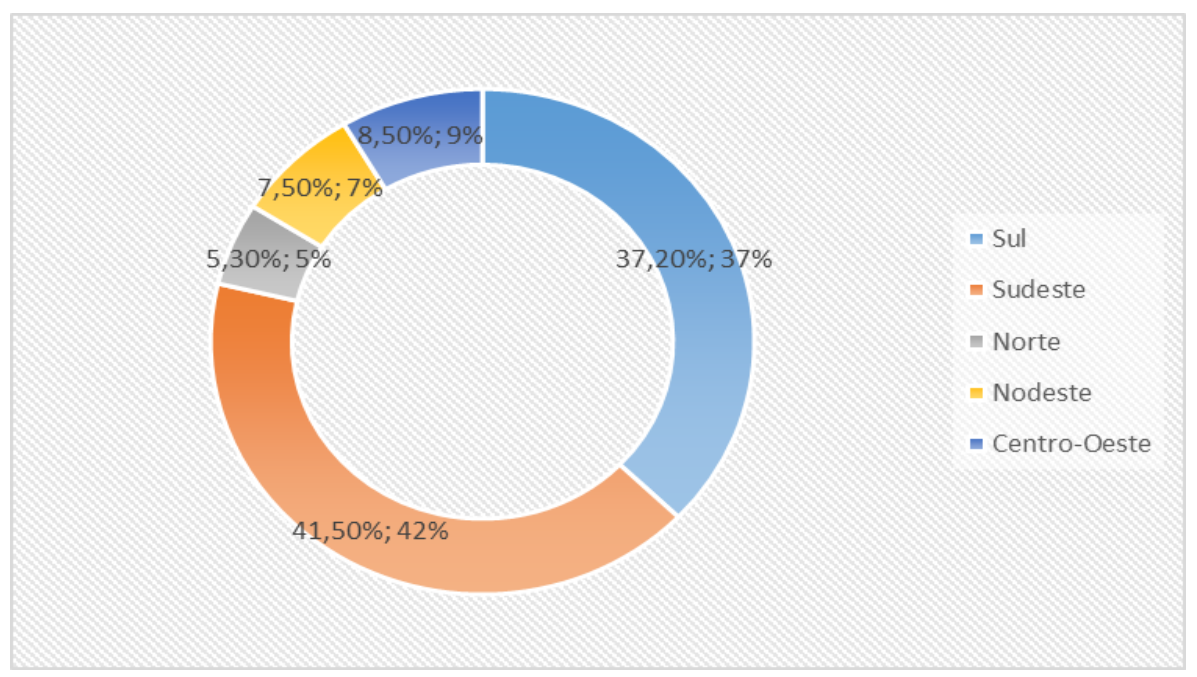

Figura 2. Distribuição de parques científicos e tecnológicos por região, CDT/UnB.

Dos nove estados da região Nordeste, seis (Alagoas, Bahia, Ceará, Paraíba, Pernambuco e Sergipe) possuem iniciativas de parques em diversos estágios, conforme Tabela 1. O estado de Pernambuco tem uma posição de liderança na região.

Tabela1. Iniciativas de parques por fase de desenvolvimento da região Nordeste. MCTI, 2014. 


\begin{tabular}{lrccc}
\hline Estado & Projeto & Implantação & Operação & Total por Estado \\
\hline Pernambuco & 0 & 1 & 1 & 2 \\
Sergipe & 0 & 0 & 1 & 1 \\
Alagoas & 0 & 1 & 0 & 1 \\
Bahia & 0 & 0 & 1 & 1 \\
Paraíba & 0 & 0 & 1 & 1 \\
Ceará & 1 & 0 & 0 & 1 \\
Rio Grade do Norte & 0 & 0 & 0 & 0 \\
Piauí & 0 & 0 & 0 & 0 \\
Maranhão & 0 & 0 & 0 & 0 \\
Total por Fase & 1 & 2 & 4 & 7 \\
Percentual por Fase & $14 \%$ & $29 \%$ & $57 \%$ & \\
\hline \multicolumn{1}{c}{ Total Geral } & & & & 7 \\
\hline
\end{tabular}

Em diversas localidades brasileiras, a instalação de um parque tecnológico trouxe benefícios importantes, promovendo uma maior interação entre academia, setor público e iniciativa privada e propiciando a demanda por empregos de alta qualificação. Nesse contexto, quanto à capacidade de geração de conhecimento, verifica-se que o estado da Bahia possui a maior quantidade de universidades/institutos federais (12) existentes nos estados da região Nordeste, um contingente de 25,5 mil pesquisadores, mestres e doutores, o maior dispêndio de C\&T da região - em torno de 159,8 milhões de reais - e aproximadamente 240 mil empresas.

\section{Senai/Cimatec}

A Instituição Científica e Tecnológica (ICT) Senai/Cimatec visa desenvolver um programa avançado de suporte tecnológico para promover a pesquisa aplicada nas tecnologias integradas da manufatura para atender a indústria brasileira.

O Senai/Cimatec possui larga experiência no desenvolvimento de projetos inovadores, sendo reconhecido pelas empresas baianas e nacionais pela sua capacidade técnica no atendimento às demandas industriais, reforçada pela experiência institucional adquirida a partir da participação da ação piloto EMBRAPII, em 2012. 


\section{Polo Embrapii IFBA}

A construção de um Polo de Inovação no Instituto Federal da Bahia (IFBA), foi iniciado em 1997, quando foi criado o Núcleo de Tecnologia em Saúde (NTS) com o objetivo de construir uma estrutura ágil e interdisciplinar que permitisse a atuação conjunta e sinérgica com os setores produtivos e governamental no campo da Saúde.

O PE-IFBA faz parte do Polo de Inovação Salvador, uma estrutura do IFBA, e está instalado no Tecnocentro do Parque Tecnológico da Bahia.

Para fazer frente às demandas do Complexo Industrial da Saúde, o Polo de Inovação Salvador possui uma equipe formada por engenheiros, físicos, especialistas em informática e em saúde que atuam em cinco laboratórios específicos Laboratório de Desenvolvimento em Engenharia Médica (LADEM); Laboratório de Engenharia Clínica (LABEC); Laboratório de Física Radiológica (LAFIR); Laboratório de Produtos para a Saúde (LABPROSAUD) e o Laboratório de Protipagem Integrada (LAPROTI) junto a outros profissionais dos inúmeros laboratórios dos diversos Campi do IFBA.

\section{PE-IFCE}

O Instituto Federal do Ceará estruturou suas atividades de pesquisa aplicada em 2002 por meio do Instituto de Telemática (ITTI). Conta com três laboratórios especializados nas áreas de redes de computadores (LAR), sistemas embarcados e inteligentes (LASI) e telecomunicações e engenharia de software (LESTE).

O Polo EMBRAPII de Inovação Fortaleza está credenciado para atuar na área de competência de Sistemas Embarcados e Mobilidade Digital, permitindo que empresas do setor industrial possam desenvolver projetos de produtos e processos inovadores.

\section{PE - IFPB}

O Instituto Federal da Paraíba é uma instituição com forte vínculo com a indústria desde a sua origem, tendo sido denominada inclusive como Escola Técnica Industrial ao longo da sua história.

Dentre os projetos já executados pelo IFPB, a maioria está ligada a tecnologias necessárias para a execução das sublinhas definidas sob a área de competência de 
credenciamento do Polo em Sistemas para Manufatura. Destacam-se neste contexto tecnologias como Software Embarcado, Eletrônica e Sistemas Inteligentes.

O IFPB - Campus João Pessoa possui infraestrutura própria com espaço físico e equipamentos de última geração adequados para a execução com sucesso de projetos de pesquisa e desenvolvimento na área de competência credenciada (EMBRAPII, 2018).

\section{Rede Nordeste de Biotecnologia (Renorbio)}

A Renorbio tem como objetivo a formação de recursos humanos com sólida base científica para suprir as demandas de desenvolvimento tecnológico dos setores acadêmicos e empresariais, que é um dos principais desafios do Brasil. É com essa perspectiva que o programa Renorbio vem sendo fundamentado. Sua proposta científica pode ser caracterizada, conceitualmente, no estudo da biologia de maneira convergente, relacionando espécies biológicas, geneticamente distantes, pela funcionalidade de seus genes, a partir do pressuposto de que as utilizações de tecnologias avançadas permitirão o estudo das bases moleculares que regulam as funções gênicas e os produtos da sua expressão, bem como dos mecanismos que as relacionam com a biologia do desenvolvimento de plantas, animais e micro-organismos.

Com foco no Nordeste, a ideia é estabelecer e estimular a massa crítica de profissionais na Região, com competência em Biotecnologia e áreas afins, para executar projetos de PD\&I de importância para o desenvolvimento dos estados da localidade.

A Rede integra cerca de 30 instituições de ensino superior. O objetivo principal é formar doutores com conhecimento aprofundado em Biotecnologia, para estarem aptos a atuar em mercados distintos, como ensino, pesquisa, prestação de serviços e indústria (RENORBIO, 2018).

\section{Embrapa Recursos Genéticos e Biotecnologia}

A Embrapa - Empresa Brasileira de Pesquisa Agropecuária, com 41 anos de experiência, é referência mundial em pesquisas e tecnologias para a agricultura. Seu objetivo é desenvolver tecnologias e sistemas de produção que contribuam para o crescimento sustentado e a competitividade da agropecuária nacional, explorando o potencial genético da biodiversidade nativa e de variedades agrícolas adaptadas, 
incorporando inovações tecnológicas às plantas, animais e micro-organismos e gerando novas alternativas de produção.

No que diz respeito às pesquisas de biotecnologia vegetal, animal e de microrganismos, os estudos têm como foco a geração de métodos específicos e sensíveis de diagnóstico de doenças; clonagem de animais de interesse pecuário; emprego de marcadores moleculares em programas de melhoramento genético; e desenvolvimento de plantas transgênicas e de bioinseticidas.

\section{Biotecnologia no Cetene}

O Cetene, Centro de Tecnologias Estratégicas do Nordeste, é uma Unidade de Pesquisa do Ministério da Ciência, Tecnologia, Inovações e Comunicações (MCTIC), criado em 2005 para apoiar o desenvolvimento tecnológico e econômico da região Nordeste, além de promover a integração entre a sociedade, a inovação e o conhecimento.

Conta com uma infraestrutura de laboratórios, multiusuários nas macroáreas de biotecnologia, microeletrônica e nanotecnologia com equipamentos e pesquisadores de altíssimo nível.

O Cetene vem atuando no desenvolvimento biotecnológico de algumas áreas consideradas estratégicas para a Região Nordeste. Os laboratórios institucionais que dão suporte a esta linha do desenvolvimento científico são: Biofábrica Governador Miguel Arraes, Laboratório de Fitoquímicos e Processos (Lafip), a Central Analítica (Cean) e o Laboratório de Bioprocessos (Labio), além da Usina Experimental Piloto Caetés, no agreste de Pernambuco.

\section{Biotecnologia Marinha no Brasil}

A Região Nordeste é, ao lado da Região Sudeste, a de maior participação na área, com grande número de grupos de pesquisa. O Ceará, é um dos estados brasileiros mais ativos na área.

O Rio Grande do Norte, possui várias empresas que utilizam organismos marinhos ou produtos derivados como matéria-prima, também apresenta grupos de pesquisa relevantes, em particular o grupo base de pesquisa: ecologia e aquicultura dos seres 
aquáticos, projetos relacionando cultivo de organismos marinhos e bioprospecção de moléculas com atividade biológica tem gerado importantes subsídios para a área.

No estado da Paraíba, atualmente um grupo vem se destacando, a Rede Interinstitucional de Algas Bentônicas, que congrega pesquisadores de várias áreas do conhecimento e de instituições nordestinas na busca de princípios ativos para uso industrial.

Em Sergipe, destaca o grupo inovações tecnológicas em produtos pesqueiros (UFS), que atua no aproveitamento de resíduos da agroindústria para a formulação de rações para peixes e camarões, no aproveitamento de resíduos de crustáceos (farinha, silagem, pigmentos, quitina e quitosana, compostagem) bem como no desenvolvimento de alimentos funcionais.

A Bahia, destacam-se os projetos das Microalgas ao Biodiesel: Inovação nos Processos Produtivos e Barateamento de Custos, e Montagem de um processo de produção de biodiesel a partir de microalgas desenvolvidos na UFBA.

\subsection{Estímulo ao desenvolvimento de novos negócios: financiamento para a inovação na Região Nordeste: agentes regionais e nacionais}

Fomentadores e financiadoras de inovação em negócios na Região Nordeste:

\section{Finep}

A Financiadora de Estudos e Projetos (FINEP) concede financiamentos reembolsáveis e não reembolsáveis a instituições de pesquisa e empresas brasileiras. Este apoio abrange todas as etapas e dimensões do ciclo de desenvolvimento científico e tecnológico: pesquisa básica, pesquisa aplicada, inovações e desenvolvimento de produtos, serviços e processos.

A Finep apoia, ainda, a incubação de empresas de base tecnológica, a implantação de parques tecnológicos, a estruturação e consolidação dos processos de pesquisa, o desenvolvimento e a inovação em empresas já estabelecidas, e o desenvolvimento de mercados. Além disso, a partir de 2012 a Finep também passou a oferecer apoio para a implementação de uma primeira unidade industrial e também incorporações, fusões e joint ventures. 
Os financiamentos reembolsáveis são realizados com recursos próprios ou provenientes de repasses de outras fontes. Os financiamentos não reembolsáveis são feitos com recursos do FNDCT, atualmente formado preponderantemente pelos Fundos Setoriais de C,T\&I. Eles são destinados a instituições sem fins lucrativos, em programas e áreas determinadas pelos comitês gestores dos Fundos.

\section{MCTI}

O Ministério da Ciência, Tecnologia e Inovação (MCTI) foi criado pelo Decreto 91.146, em 15 de março de 1985. Sua área de competência foi estabelecida pelo Decreto no 5.886, de 6 de setembro de 2006 .

Como órgão da administração federal direta, o MCTI tem como competências:

- Política nacional de pesquisa científica, tecnológica e inovação;

- Planejamento, coordenação, supervisão e controle das atividades da ciência e tecnologia;

- Política de desenvolvimento de informática e automação;

- Política nacional de biossegurança;

- Política espacial;

- Política nuclear;

- Controle da exportação de bens e serviços sensíveis.

\section{Banco do Nordeste}

O Banco do Nordeste atua para o desenvolvimento da Região Nordeste reconhecido pela sua capacidade de promover o bem-estar das famílias e a competitividade das empresas da região. As fontes dos recursos são, em grande parte, do Fundo Constitucional de Financiamento do Nordeste (FNE).

O FNE Inovação, objetiva financiar a implantação, expansão, modernização, reforma e relocalização que viabilizem inovações em produtos, serviços, processos, métodos organizacionais e métodos de marketing nos empreendimentos com um público-alvo de empresas brasileiras e produtores rurais, cooperativas, associações de produtores.

Por outro lado, o FNE Semente, fomenta o empreendedorismo, atraindo e mantendo na região capital humano e projetos de negócios com alto potencial de crescimento, por meio de apoio a empresas nascentes, startups, em estágio de 
implementação com um público-alvo mini, micro e pequenas empresas e microempreendedores individuais com projetos de negócios inovadores.

Parceria entre BNB e Embrapii apoia projetos de pesquisa, desenvolvimento e inovação, especialmente de pequenas e médias empresas.

O apoio do Banco do Nordeste é, essencialmente, por meio de financiamento reembolsável a empresas industriais, no âmbito do Programa de Financiamento à Inovação (FNE-Inovação), e eventual financiamento não reembolsável a instituições de pesquisa científica e tecnológica, devidamente credenciadas pela Embrapii, no âmbito do Fundo de Desenvolvimento Econômico, Científico, Tecnológico e de Inovação (Fundeci). O apoio da Embrapii tem por meio da intermediação entre empresas industriais, Unidades Embrapii e Polos Embrapii IF com o BNB (EMBRAPII, 2018).

\section{Embrapii}

A Embrapii atua por meio da cooperação com instituições de pesquisa científica e tecnológica, públicas ou privadas, tendo como foco as demandas empresariais e como alvo o compartilhamento de risco na fase pré-competitiva da inovação. Trata-se de uma organização social criada pelo MCTI, em parceria com a Confederação Nacional da Indústria (CNI), e com o apoio da Financiadora de Estudos e Projetos (Finep). Tem por objetivo fomentar projetos de cooperação entre empresas nacionais e instituições de pesquisa a geração de produtos e processos inovadores. São apoiáveis projetos com desenvolvimento tecnológico e a inovação de interesse estratégico para o País.

A atuação de Polos EMBRAPII que estão voltados ao atendimento das demandas do setor produtivo, por pesquisa, desenvolvimento e inovação (PD\&l) e à formação profissional para as atividades de PD\&I na indústria.

\section{Comentários sobre o atual ecossistema de inovação em bionegócios no Nordeste Brasil}

A buscas pelos dados presentes neste estudo explicita a necessidade de atualizar as informações sobre o ecossistema de inovação da região Nordeste, as referências estão desatualizadas e já não refletem o momento atual. Assim, trabalhos como estes são importantes para atualização e fazer uma reflexão das informações disponíveis para esta região. A leitura dos textos explicita a evolução do ecossistema de inovação no Nordeste. 
O ecossistema de inovação em bionegócios no qual está inserida a Rede Nordeste de Biotecnologia (Renorbio) está em processo de crescimento apontados pelo crescimento de entidades de pesquisa voltadas para descobertas biotecnológicas, desenvolvimento de bionegócios e pela integração entres várias entidades governamentais e privadas. Estes processos de crescimento em bionegócios necessita de gestão para que possa avançar.

A gestão é relevante para que os agentes do ecossistema de bionegócios possam interagir e, portanto, tanto o desenvolvimento biotecnológico como processos de gestão possam coevoluir.

\section{Percepção dos gestores usuários do Sistema nacional de Inovação}

As percepções dos gestores são apresentadas segundo as dimensões que foram utilizadas no roteiro de entrevista apresentado no capítulo metodologia: estratégica; interação entre agentes; e, estrutura organizacional.

\section{Dimensão estratégica}

A partir das respostas e manifestações dos gestores entrevistados houve convergência em uma característica geral básica atual do ecossistema de inovação no Brasil, a saber:

- A dificuldade de visão estratégica consolidada a respeito da importância política do papel da inovação para a competitividade das empresas e desenvolvimento socioeconômico.

Dessa questão de natureza crônica decorrem vários aspectos inibidores para a prática da inovação pelas empresas no Brasil: longo prazo;

- Insegurança em decisão de investimentos em projetos de inovação de

- $\quad$ Ambiente com predominância de fatores inibidores à decisão por projetos de inovação com maior risco, ou seja, um ambiente "avesso ao risco";

- Mecanismos de financiamento para inovação com maturidade incompatível para a aplicação das políticas públicas deliberadas;

- Situação de incerteza alta encarece o investimento em inovação; e,

- A situação de insegurança jurídica, muito presente no ambiente brasileiro nas últimas décadas, que gera "altos e baixos" conjunturais, afetando a saúde e a sustentabilidade dos negócios. 
Do ponto de vista da gestão empresarial, pode-se registrar um conceito de aplicação genérica que traduz a importância estratégica da inovação para as empresas. 0 propósito deve ser: "Inovar para a eficiência" e não "inovar para cobrir a ineficiência".

Em síntese, do ponto de vista estratégico, o cenário básico do ecossistema de inovação no Brasil tem natureza adversa dos pontos de vista, fiscal, de investimento e de tolerância ao risco.

\section{Dimensão interação entre agentes}

Quanto aos aspectos ligados à interação entre os agentes do ecossistema de inovação, de acordo com a manifestação dos gestores, foi reconhecido um progresso no ambiente nacional, a partir do ano 2.000 .

Entretanto, essa evolução deveria ocorrer em ritmo mais acelerado. A realidade indica que esta interação se tornou decisória para o sucesso da inovação e, por conseguinte, no aproveitamento de oportunidades de negócios.

Além da interação basilar entre agentes de produção de conhecimentos básicos (academia), conhecimentos aplicados (instituições de pesquisa e congêneres) e as empresas, a interação entre empresas também tem ganho destaque vis-à-vis da possibilidade de sucesso de inovações. Em particular, foi destacado a interação das empresas de porte médio e grande com as empresas nascentes, ditas startups. Fenômeno que tem tido aumento expressivo no ambiente dos negócios no Brasil. E não só.

Nesse aspecto, surge um desafio de natureza gerencial que é a capacitação do quadro de gestores da inovação em dar eficiência à estratégia de cooperação. Na prática, esse desafio organizacional se traduz em ter eficiência em gerir o "trabalhar juntos". Equipes de natureza institucional distintas "multi tudo", para trabalhar em inovação, em si, uma atividade transversal.

Pelos depoimentos colhidos, as empresas estão se equipando de metodologias e técnicas que as capacitem para sucesso da gestão desse tipo de operação de complexidade gerencial elevada.

No que respeita o relacionamento com fontes de fomento para inovação foi dado destaque para a dificuldade de acesso a parte dos recursos para investimento em inovação. Em particular, a privação de acesso aos recursos do mecanismo de subvenção 
econômica para micro, pequenas e médias empresas ou para empresas que não tenham lucro.

No caso das duas startups que fizeram parte desse estudo, houve destaque para a importância do papel das estruturas, públicas e privadas, dedicadas à incubação e aceleração de negócios inovadores.

\section{Dimensão organização interna}

Independentemente do tamanho da empresa, há consenso de que projetos de inovação não se executam mais apenas com os recursos internos, infraestrutura, profissionais e recursos financeiros.

A depender do tipo de inovação, incremental ou radical, as empresas dispõem de processos próprios de gestão da inovação.

Entre as empresas de grande porte foi identificada a existência de destinação de recursos financeiros para processos de parceria estratégica com startups. Sob diferentes metodologias, mas programas de caráter permanente. Essa iniciativa decorre também da necessidade estratégica de rastreamento, flexibilização e tempo menor possível de acesso a novos conhecimentos e oportunidades de negócios.

Uma questão crítica, unânime entre os gestores parte deste estudo, é a escassez de recursos humanos qualificados, tanto do ponto de vista técnico quanto gerencial.

\section{CONSIDERAÇÕES FINAIS}

A região Nordeste possui diversas entidades envolvidas no desenvolvimento biotecnológico, entretanto foi observado que a quantidade de bionegócios, em pleno funcionamento, é baixa quando comparada com o número de agentes que buscam desenvolver um bionegócio. Foi observado que muitos dos agentes presentes atuam isoladamente o que impede o crescimento conjunto.

Pelas informações levantadas, neste trabalho, pode ser observado que o gargalo da região Nordeste, no que se refere ao desenvolvimento de bionegócios, é a gestão. Os órgãos governamentais financiadores e autarquias de pesquisa precisam interagir melhor com entidades privadas, buscando o desenvolvimento científico, tecnológico e 
biotecnológico para que ocorra o desenvolvimento de novos bionegócios e, consequentemente, o desenvolvimento de toda a região Nordeste.

Por fim, o desenvolvimento do bionegócio na região Nordeste, perpassa por uma mudança da forma como os recursos humanos estão sendo formados. São estes agentes que são capazes de modificar a estrutura existente e fazer com que o ecossistema de inovação possa interagir melhor e progredir.

\section{REFERÊNCIAS BIBLIOGRÁFICAS}

ABREU, Paulo. R. M; CAMPOS, Newton, M. O panorama das aceleradoras de startups no Brasil. CreateSpace Independent Publishing Plataform. EUA, 2016.

ANPROTEC - Panorama 2005 ANPROTEC, 2005. Disponível em: < http://www.anprotec.org.br/ArquivosDin/Panorama 2005 pdf 11.pdf> Acesso em: 03 Jun 2018.

ANPEI. Associação Nacional de Pesquisa e Desenvolvimento de Empresas Empreendedoras. Mapa do Sistema Brasileiro de Inovação. Disponível em: < http://anpei.org.br/conteudos/> Acesso em 26 de julho de 2018.

ARAÚJO Filho, G. Iniciativas em bionegócios e o programa pappe-subvenção no estado do Amazonas. Revista T\&C Amazônia, Ano VIII, n. 19, 2010.

BANCO DO NORDESTE. Fomento à Pesquisa e Inovação no Banco do Nordeste. 11 ENIFarMed Como estabilizar o financiamento para subvenção econômica para empresas inovadoras? 2017. Disponível em:

<http://www.abifina.org.br/arquivos/download/11enifarmed2017.pdf> Acesso em: 01 Ago 2018.

BESSANT, John; TIDD, Joe. Inovação e empreendedorismo. S/L: bookman, 2009.

BOARI, Cristina; LIPPARINI, Andrea. Networks within Industrial Districts: Organising Knowledge Creation and Transfer by Means of Moderate Hierarchie. Journal of Management and Governance, v. 3; n. 1, p. 339-360, 1999.

BRASIL, Casa Civil. Decreto N 9.283, de 7 de fevereiro de 2018.

BRUNO, Marcos A. C; VASCONCELOS, Eduardo. Applying a management framework to three high-sharing technological alliances. Rivista Finanza, Marketing e produzione, Milano, v. 21, n. 2, p. 107-126, giugno, 2003.

CENTRO BRASILEIRO DE ANÁLISE E PLANEJAMENTO. CEBRAP, 2011. Disponível em: < http://cebrap.org.br/> Acesso em: 5 Jul 2018.

CHESBROUGH, Henry. Open Innovation. Boston: Harvard Business School Press, 2003. CONFEDERAÇÃO NACIONAL DA INDÚSTRIA (CNI). CNI Sustentabilidade, 2017. Disponível em: < http://www.portaldaindustria.com.br/cni/canais/cni-sustentabilidade/edicao2017/> Acesso em: 31 Mai 2018 
CROCCO, Marcos; DINIZ, Clélio C.; SANTOS, Fabiana. Conhecimento, inovação e desenvolvimento regional/local. Economia regional e urbana: Contribuições teóricas recentes. Belo Horizonte: UFMG, p. 87-122, 2006.

DOSI, Giovanni. The Nature of the Innovative Process. In: DOSI, G. et al. Technical Change and Economic Theory. London: Pinter, 1988.

DOZ, Yves L.; HAMEL, Gary. Alliance Advantage. The art of creating value throught partnering. Boston: Harvard Business School Pressa, 1998.

Empresa Brasileira de Pesquisa e Inovação Industrial (EMBRAPII). Polos EMBRAPII IF, 2018. Disponível em: < http://www.embrapii.org.br/categoria/polos-embrapii-if/>. Acesso em: 26 Jul 2018.

ETZKOWITZ, Henry; LEYDESDORFF, Loet. Introduction to special issue on science policy dimensions of the Triple Helix of university-industry-government relations. Science and Public Policy, v. 24, n. 1, p. 2-5, 1997.

FELIPE, Maria S.S. Desenvolvimento Tecnológico e Inovação no Brasil desafios na área de biotecnologia. Novos Estudos. p.78, 2007.

FERREIRA, Jamila L.; RUFFONI, Janaina; CARVALHO, Alexsandro M. Dinâmica da difusão de inovações no contexto brasileiro. Revista Brasileira de Inovação, Campinas (SP), v. 17, n.1, p. 175-200, 2018.

GIL, Antônio C. Como elaborar projetos de pesquisa. 5. ed. São Paulo. Atlas, 184p., 2010. GLICK, Bernard; PASTERNAK, Jack. Molecular Biotechnology: Principles and Applications of Recombinant DNA. - 3rd ed. Sigma Publishing, 784 p., 2003.

GUEDES, Tales. Networks of innovation and the need for systemic science and technology policies: the Brazilian experience. Tese de doutorado. University of Manchester, 1998.

JOHNSON, Mark; CHRISTENSEN, Clayton; KAGERMANN, Henning. Reinventing your business model. Boston: Harvard Business School Press, 2008.

JUDICE, Valéria M.M.; BAÊTA, Adelaide M.C. Modelo Empresarial, Gestão de Inovação e Investimentos de Venture Capital em Empresas de Biotecnologia no Brasil. RAC. v.9, n.1, p.171-191, 2005.

KOROBBINSKI, Raquel R.O grande desafio empresarial de hoje: a gestão do conhecimento. In: Perspect. Cienc. Inf. Belo Horizonte. v.6, n.1, p.107-116, 2001.

LEITE, Luiz F. Inovação: o combustível do futuro. Rio de Janeiro: Petrobrás/Qualitymark, 2005.

MATIAS-PEREIRA, José; KRUGLIANSKAS, Isac. Gestão de inovação. A lei de inovação tecnológica como ferramenta de apoio às políticas industrial e tecnológica do brasil. RAEeletrônica, v.4, n.2, 2005.

MATOS, F. Qual a região campeã em densidade de startups no Brasil? Você vai se surpreender. CASE, 2017. Disponível em: < https://link.estadao.com.br/blogs/felipe- 
matos/qual-a-regiao-campea-em-densidade-de-startups-no-brasil-voce-vai-sesurpreender/> Acesso em: 30 Jun 2018.

MIGUEL, Laís M. Uso Sustentável da Biodiversidade na Amazônia Brasileira: experiências atuais e perspectiva das bioindústrias de cosmético e fitoterápico. São Paulo, USP Programa de Pós-Graduação em Geografia Humana. p.171, 2007.

MINISTÉRIO DA CIÊNCIA, TECNOLOGIA E INOVAÇÃO (MCTI). Relatório de Gestão do Exercício de 2014. Disponível em: < http://www.ibict.br/servico-de-informacao-aocidadao-1/idSisdoc 8749361v109RelatorioGestao2.pdf> Acesso em: 28 Mai 2018.

Rede Nordeste de Biotecnologia (RENORBIO), 2018. Disponível em: < https://www.unifor.br/web/pos-graduacao/renorbio> Acesso em: 25 Jul 2018.

RIBEIRO, Paulo V.V. Inovação Tecnológica e Transferência de Tecnologia. UNB, 2001.

SILVA, Denise R.M.; FURTADO, André T. Modelos teóricos e interesses de mensuração no surgimento da pesquisa de inovação brasileira (Pintec). Revista Brasileira de Inovação, Campinas (SP), p. 97-128, 2017.

SILVEIRA, José Maria F.J.; FUTINO, Ana M.; OLALDE, Alícia R. Biotecnologia: corporações, financiamento da inovação e novas formas organizacionais. Economia e Sociedade, Campinas, v. 11, n. 1 (18), p. 129-164, 2002.

SMITH, Kade. Economic infrastructures and innovation systems. In: EDQUIST, C. (Ed.). Systems of innovation: technologies, institutions and organizations. London: Pinter, p. 86106, 1997.

SOUSA, Kleber A. A dinâmica da inovação em bionegócios no Estado do Amazonas: um estudo dos segmentos de alimentos e bebidas e fitoterápicos e fitocosméticos. Tese de Doutorado - Universidade Federal do Amazonas, Manaus, 146 f., 2014.

SOUSA, Kleber A.; FIGUEIREDO, Giane L.A.S. Bionegócios e desenvolvimento alternativo no estado do Amazonas (Brasil). Revista de História da UEG, Anápolis, v.4, n.2, p. 139159, 2015.

SPAREMBERGER, Ariosto; ZAMBERLAN, Luciano. Marketing Estratégico. Ijuí: Ed. Unijuí, $212 p, 2008$.

TORRES, Pedro H.; BOTELHO, Marisa R.A. Financiamento à inovação e interação entre atividades científicas e tecnológicas: uma análise do Pappe. Revista Brasileira de Inovação, Campinas (SP), p. 89-118, 2018.

VASCONCELLOS Alexandre G.; FRICKMAN Fabiana S.S. Oportunidades para a inovação e aproveitamento da biodiversidade amazônica em bases sustentáveis. Revista T\&C

Amazônia, ano VIII, n. 19, II semestre de 2010.

VICENZI, Raul. Biotecnologia de alimentos. Ijuí/RS. Disponível em: < https://pt.scribd.com/doc/6703108/Apostila-Biotecnologia-de-Alimentos> Acesso em: 26 Jul 2018.

VILHA, Anapatrícia M. Gestão de Inovação nas Empresas. São Paulo: Agência Brasileira de Desenvolvimento Industrial - Prefeitura de Diadema - SINDIPLAST - SINDIBOR, 2010. 
VILLELA, Tais N., MAGACHO, Lygia A.M. Abordagem histórica do Sistema Nacional de Inovação e o papel das Incubadoras de Empresas na interação entre agentes deste sistema. XIX Seminário Nacional de Parques Tecnológicos e Incubadoras de Empresas: Inovação e Empreendedorismo para o desenvolvimento. Florianópolis, 2009.

YOSHINO, Michael Y.; RANGAN, Snirivasa. Strategic alliances. An entrepreneurial approach to globalization. Boston: Harvard Business School Press, 1995. 